Old Dominion University

ODU Digital Commons

VMASC Publications

Virginia Modeling, Analysis \& Simulation Center

2011

\title{
Selection of Source and Use of Traffic Information in Emergency Situations
}

R. Michael Robinson

Old Dominion University, rmrobins@odu.edu

Asad Khattak

Old Dominion University

Follow this and additional works at: https://digitalcommons.odu.edu/vmasc_pubs

Part of the Civil Engineering Commons, Emergency and Disaster Management Commons, Transportation Commons, and the Transportation Engineering Commons

\section{Repository Citation}

Robinson, R. Michael and Khattak, Asad, "Selection of Source and Use of Traffic Information in Emergency Situations" (2011). VMASC Publications. 28.

https://digitalcommons.odu.edu/vmasc_pubs/28

\section{Original Publication Citation}

Robinson, R. M., \& Khattak, A. (2011). Selection of source and use of traffic information in emergency situations. Transportation Research Record, 2234, 71-78. doi:10.3141/2234-08

This Article is brought to you for free and open access by the Virginia Modeling, Analysis \& Simulation Center at ODU Digital Commons. It has been accepted for inclusion in VMASC Publications by an authorized administrator of ODU Digital Commons. For more information, please contact digitalcommons@odu.edu. 


\title{
Selection of Source and Use of Traffic Information in Emergency Situations
}

\author{
R. Michael Robinson and Asad Khattak
}

The access and the use of advanced traveler information systems (ATISs) by drivers during normal commuting have been extensively assessed and analyzed. Emergency managers and transportation officials have extended the results of studies of ATIS use under routine conditions to emergency scenarios under the assumption that drivers' responses to information under emergency conditions mimic those seen under normal driving conditions. A recent survey of potential hurricane evacuees suggests the need to revisit this assumption. Results indicate that although commercial radio reports and variable message signs continue to be the sources of traffic information cited the most frequently, other information sources (mobile phones, in-car systems such as Global Positioning System devices, and the Internet) have significantly increased in importance. Rapid growth in user rates and the relatively low cost of implementation suggest that a revision of plans for emergency transportation information communications may be warranted. Better, more effective use of ATISs during emergency situations, especially when traffic incidents occur, may lead to improved and more reliable travel times and improved safety and emergency response. With the use of factor analysis, four driver personalities are identified, with each one characterized by the proclivity for and response to traffic information. This information will be of interest to developers and users of ATISs and to those responsible for emergency management and transportation planning.

For decades, drivers have relied on commercial radio traffic reports to plan trips, adjust departure times in response to reported conditions, and adjust routes to minimize travel times. The 1990s saw increasing use of variable message signs (VMSs), especially in large metropoli$\tan$ areas and along key freeway sections. More recently, drivers have begun to rely on three relatively new and innovative technology sources: Global Positioning System (GPS) devices, mobile phones, and the Internet.

In general, earlier studies focused on the use of advanced traveler information systems (ATISs) during routine commuting; the findings of those studies were assumed to apply to emergency situations. The research described here explores driver preferences and choices in a hurricane evacuation and the sources and relative influences of the traffic information most frequently used by evacuees. It also provides insight into the importance of increasing driver perceptions of

R. M. Robinson, Virginia Modeling, Analysis, and Simulation Center, Old Dominion University, Suffolk, VA 23435. A. Khattak, Department of Civil and Environmental Engineering, 135 Kaufmann Hall, Old Dominion University, Norfolk, VA 23529. Corresponding author: R. M. Robinson, RMRobins@odu.edu.

Transportation Research Record: Journal of the Transportation Research Board, No. 2234, Transportation Research Board of the National Academies, Washington, D.C., 2011, pp. 71-78.

DOI: 10.3141/2234-08 safety and well-being on route choice decisions. Results of a survey of more than 800 potential hurricane evacuees allow an assessment of reliance on ATISs and how it has recently grown. The study explores how emergency management agencies should place increased emphasis on communication methods in emergency as well as routine traffic management plans. The survey examines whether the provision of information that increases evacuees' confidence and sense of security when they take an alternate route was more likely to influence driver behavior in emergency situations.

To understand the proclivity for travel information, factor analysis was used to identify four types of driver personalities, each of which is characterized by differences in use and influence of ATISs. By better understanding which drivers are likely to be influenced by ATISs and tailoring traffic information content, emergency management and traffic control officials can anticipate and prompt driver response, thereby reducing travel times, increasing travel time reliability, and improving the effectiveness of the overall traffic network.

\section{LITERATURE REVIEW}

Dow and Cutter examined the changing relationships between household evacuation decisions and emergency management practices as the availability and diversity of information on hurricanes increased (1). They found that residents actively sought information from an array of sources and considered that information in light of their own past experiences and understanding of risks to make decisions on whether to evacuate. The study noted that staying abreast of advances in communication technology and understanding their use in risk communication and management will be key to success in future hurricane seasons.

Prater et al. examined the distribution of information during the 1999 Hurricane Bret, a strong Category 4 hurricane, including how information was promulgated before and during the storm (2). They noted differences in the ways in which residents used various information sources in the evacuation decision. The importance of a well-planned and well-coordinated communications policy was emphasized. The report included recommendations to use all available media to educate the public in advance of a storm, particularly on plans for reversing traffic direction on Interstate highway lanes (contraflow traffic) and to increase awareness of alternate routes and destinations. It also recommended the greater use of signs to increase public awareness of evacuation routes and suggested that during an evacuation, officials should work closely with local radio stations to improve reporting on evacuation traffic conditions.

Wolshon et al. addressed several issues involving intelligent transportation systems (ITSs) (3). The study noted that as a result of inadequacies in ITSs during evacuations for Hurricanes Georges and Floyd, emergency managers were unable to direct traffic from 
overloaded routes to nearby roads that carried little or no traffic. It also pointed out that much of the nation's ITS infrastructure is in urban areas, whereas evacuation routes are primarily through rural areas, suggesting the possible need for infrastructure modifications. The authors noted that several states plan to overcome this problem by using portable message signs and highway advisory radio.

Mehndiratta et al. used data from the ongoing Puget Sound, Washington, Regional Council Transportation Panel travel diary study to identify likely ATIS users (4). The paper reported that traffic information users tended to be younger and wealthier and were more likely to be male, more likely to have children aged 6 to 17 years, and more conversant with technology than the general population. Goulias et al., using data from a version of the same Puget Sound study from a later year, examined the relationships between technology ownership and availability, ATIS awareness, and frequency of ATIS use (5). They focused on awareness and use of available information.

Khattak et al. sought a better understanding of drivers' en route decision making in response to traffic delays as a contribution to efforts seeking to reduce traffic congestion (6). Their work identified several key factors influencing the likelihood that drivers will divert, including information source, past driver behavior, gender, and driver stated preferences about diverting.

The study also showed that real-time traffic information broadcasts provided a basis for en route diversion decisions and suggested that the effectiveness of radio broadcasts would increase with information about delay lengths and traffic conditions on alternate routes. Interestingly, even though the traffic situations queried involved daily commuters, the study revealed a significant disparity between stated intentions and actual behavior.

In a subsequent study, Khattak et al. investigated driver responses to pretrip and en route congestion information (7). Surveys of automobile commuters in the San Francisco Bay Area, California, gathered information on traveler age, gender, and occupation; normal travel patterns; pretrip responses to unexpected congestion information; en route response to unexpected congestion information; and traveler willingness to change driving patterns. The study found that a lack of experience with alternate routes was a critical factor in travelers' willingness to divert in response to incidents and suggested that real-time information on alternatives would encourage diversions.

Khattak et al. conducted a study to assess whether increasing travelers' access to public traffic information systems is associated with increased use of the information in decision making and also which (if any) information medium is associated with a greater likelihood that travelers will change their travel decisions (8). The study found that travelers are generally reluctant to make changes to routine plans because of behavioral inertia, even when information that would improve a specific commute was provided. A significant increase in the likelihood of plan changes occurred when more than one source of traffic information was used. Of all technologies assessed in the study, the Internet was associated with the highest propensity to change travel decisions (time, mode, route, or trip cancellation), followed by radio and television. Radio was the dominant influence on changes to routes only. However, the authors note that at the time of the survey, few VMSs were deployed in the area surveyed.

Scheisel and Demetsky assessed the influence of the messages on dynamic message signs (DMSs; equivalent to the VMSs discussed elsewhere in this report) on a traveler's choice to change his or her route (9). Data were collected from loop detectors, and the traffic volumes detected when the DMS system was in use were compared with those detected during similar periods when the system was not in use.
Analyses sought to determine the value of any diversion prompted by the DMS system. Although the results of the study were inconclusive, the report provides a good discussion of the study process and sensitivity analysis.

Levinson and Huo assessed the effectiveness of VMSs on route guidance using traffic information gathered before and after installation of VMSs in Minnesota (10). Information was taken from empirical traffic data from inductive loop detectors and incident data and was used to evaluate the networkwide travel time benefit of the VMS systems. They found that VMSs produced no significant reduction in travel times but could reduce total traveler delay.

Maier-Speredelozzi et al. produced a methodology for developing a library of messages appropriate for use on VMSs to enhance disaster response preparedness (11). As part of their study, a survey collected information on driver characteristics, including the influence of VMSs.

Ye et al. evaluated the use of the rural transportation infrastructure in evacuations by looking at current practices in the northern Gulf of Mexico (12). The work used survey results from 18 state emergency management agencies and district transportation offices to investigate rural evacuation behavior, including the frequency of information source use.

Robinson and Khattak identified the variables associated with the decision to alter routes and proposed a decision-making model for use in a dynamic traffic simulation as a means for evacuation decision makers to assess the impacts of driver decisions (13). This new study builds on the previous one by further assessing the impact of information source selection, analyzing the importance of traffic information content, and using factor analysis techniques to identify four traffic information user personality groups and allow more effective use of ATISs.

Robinson used a dynamic traffic simulation and survey results to forecast both the route choice decisions made by evacuees when they were confronted with congestion and the impacts of these decisions on overall traffic network performance (14).

Gaps in the literature include the impacts of stresses during emergency situations and potential communication system failures on the traffic information that travelers select for use, the socioeconomic segmentation of users of advanced technology in emergencies, and a focused assessment of the importance of information content in a hurricane evacuation scenario.

\section{METHODOLOGY}

A behavioral survey with stated preference and revealed preference questions gathered information on potential evacuees, their use of traffic information, and the potential influence of that information. After responses that were substantially incomplete were deleted, 841 valid responses were obtained. A summary of the characteristics of the sampled population and comparable regional values are provided in Table 1. In general, the respondents were older, better educated, and wealthier than the general regional population. However, with the exception of the youngest participant group (ages 18 to 24 years) and the lowest income group (annual income of less than $\$ 20,000)$, each demographic group examined had ample responses to allow valid assessment. When the respondents were segmented into groups according to demographic characteristics (age, gender, etc.) and the responses were statistically weighted to better reflect each group's fraction of the total regional population, the analyses with weighting factors were consistent with unweighted analyses. 
TABLE 1 Characteristics of Survey Respondents ( $n=841)$ and Regional Demographics of Hampton Roads

\begin{tabular}{lcc}
\hline & Survey $(\%)$ & Region $^{a}(\%)$ \\
\hline Gender & & \\
\hline Male-female & $48-52$ & $49-51$ \\
No. of male-no. of female & \\
\hline Age (years) & $392-394$ & \\
\hline 18-24 & & \\
25-35 & 2.4 & 15 \\
36-45 & 11.4 & 18 \\
46-55 & 19.3 & 20 \\
56-65 & 29.8 & 19 \\
$>65$ & 23.4 & 13 \\
Not reported & 10.0 & 15 \\
\hline Education Level & 3.7 & \\
\hline Up to high school graduate & 5.1 & 34 \\
Some college & 18.9 & 29 \\
College graduate & 36.3 & 14 \\
Advanced college degree & 35.9 & 11 \\
Not reported & 3.7 & \\
\hline Approximate Annual Income (\$) & & 37 \\
\hline Less than 20,000 & 1.1 & \\
20,000-50,000 & 13.7 & \\
50,000-75,000 & 18.5 & \\
75,000-100,000 & 58.0 & \\
More than 100,000 & 8.7 & \\
\hline
\end{tabular}

${ }^{a}$ Regional values were obtained from the Virginian-Pilot summary of The Scarborough Report 2006, Release 2, at http://thevirginian pilot.com/advertising/demoLife.html. Accessed July 24, 2009.

${ }^{b}$ Fifty-five respondents did not report their gender.

The survey identified the information types and sources that potential hurricane evacuees most frequently used. Each respondent was asked about the likelihood that he or she would divert or remain on the current route when he or she was delayed by congestion, when different information content was presented via different sources. Responses were queried at four time points. A five-level Likert scale was used. Respondents also reported their level of agreement with statements regarding their frequency of accessing ATISs, the influence of ATISs on their route choices, and the format of traffic information desired. Additional information on each driver's personality was gathered, including aggressiveness, confidence in the traffic information provided, extent of preparedness for an evacuation, and willingness to take risks. A failure to respond was given a score equivalent to a neutral response; this combination represented less than $5 \%$ of the total responses for the questions and statements evaluated. For analysis, the two agree-level responses and the two disagree-level responses were combined, producing binomial results. Results were analyzed with SPSS and Microsoft Excel statistical software. Statistical significance was assessed by the use of confidence intervals, chi-square distribution testing, and Welch's $t$-test. Results were also assessed with factor analysis techniques.

\section{INFORMATION SOURCES, INFORMATION CONTENT, AND INFLUENCE}

Five traffic information sources (radio, mobile phones, highway message signs, in-car GPS, and the Internet) were listed on the survey, and respondents were asked to indicate their frequency of access and use of those sources while driving. To assess the influence of the information, respondents were asked if they had altered course because of information obtained from the indicated sources. These answers were compared with the respondents' separately queried, self-reported likelihood of altering course during an evacuation to avoid congestion.

Essentially all (99.7\%) respondents reported using traffic information sources for routine travel. Radio traffic information reports were easily the most popular source, used by just over $90 \%$ of respondents. VMSs were used by approximately $70 \%$ of respondents, whereas one-half used mobile phones and approximately one-third used GPS and the Internet. Some combination of radio, VMS, or phone system was used for traffic information by $98.3 \%$ of all respondents. The vast majority of respondents reported using multiple sources of traffic information, with $88.9 \%$ using two or more sources, $59.4 \%$ using three or more, and $29.6 \%$ using four or more. Figure 1 shows the percentage of respondents who reported using each of the five sources individually.

Table 2 indicates the percentage of respondents who reported routine use of two information sources in all possible pairings, with shaded blocks indicating the percentage of respondents using the

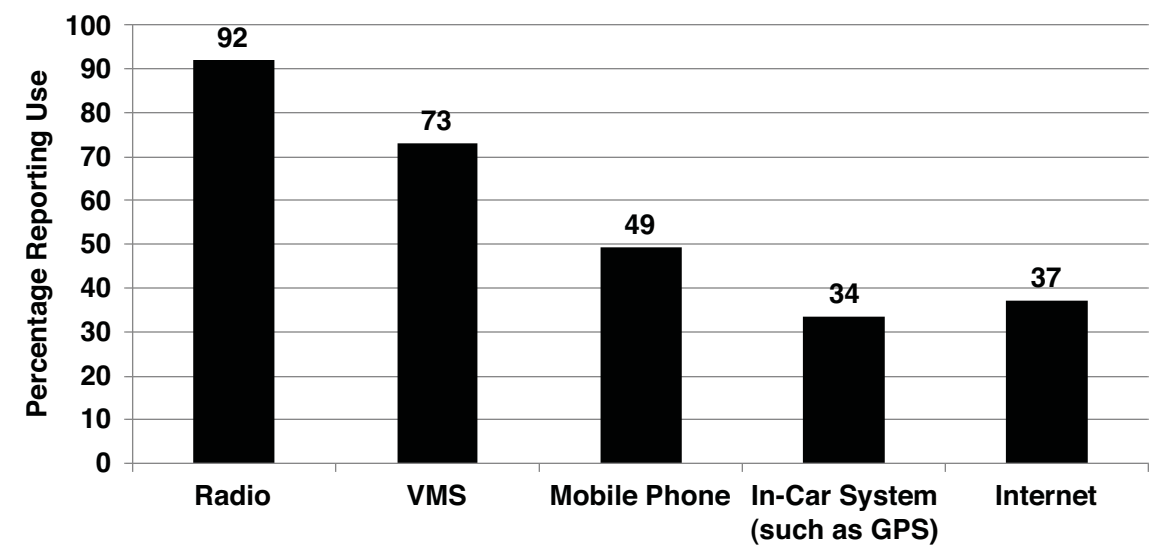

FIGURE 1 Percentage of sample population reporting use of indicated traffic information sources. 
TABLE 2 Reported Use of Traffic Information Sources and Pair of Source Combinations (Percentage of All Respondents)

\begin{tabular}{lccccc}
\hline & Radio & VMS & $\begin{array}{l}\text { Mobile } \\
\text { Phone }\end{array}$ & $\begin{array}{c}\text { In-Car System } \\
\text { (such as GPS) }\end{array}$ & Internet \\
\hline Radio & 92.1 & 67.5 & 45.2 & 30.1 & 31.2 \\
VMS & 67.5 & 73.0 & 39.6 & 21.6 & 28.4 \\
Mobile phone & 45.2 & 39.6 & 49.4 & 25.5 & 19.8 \\
In-car GPS & 30.1 & 25.5 & 21.6 & 33.5 & 14.1 \\
Internet & 31.2 & 28.4 & 19.8 & 14.1 & 37.0 \\
\hline
\end{tabular}

indicated source. For example, $92.1 \%$ of all respondents received traffic information via the radio and $73.0 \%$ received traffic information via VMSs; $67.5 \%$ of all respondents received information via both the radio and VMS.

Figure 2 shows the reported use of each information source by gender group. Equal proportions of males and females reported that they had altered their routes during past routine driving in response to traffic information on VMSs, although males tended to be more suspicious of the information's accuracy. Likewise, individuals of both genders anticipated the use and influence of VMSs in a hurricane evacuation at similar rates. Although some variability is seen, differences in use rates were not statistically significant when the rates were assessed by the three statistical analysis methods (confidence intervals, chi-square distribution testing, and Welch's $t$-test) with significance levels ( $p$ values) of .05 .

Figure 3 shows the percentage of each age group reporting use of particular information sources. Again, the dominant use of radio and VMS traffic information is easily seen. Figure 3 shows that the group aged 36 to 45 years old reported higher rates of usage for all information sources than the rate reported by the total sample population. However, none of the differences between individual age groups was statistically significant (at $p=.05$ ). The youngest age group (18 to 24 years old) was more likely to use the Internet and VMSs than others, but with just 20 group members, the group was too small for credible statistical assessment of their use of information sources.

Similar results were noted when information source selections were compared with annual household income. For all income groups, radio and VMSs were used much more frequently than other sources, followed by mobile phones. Although some slight variability between different income groups was noted, none was statistically significant.

The proportion of respondents who reported using traffic information sources was significantly higher than that found in previous studies, such as those of Mehndiratta et al. (4), Yim et al. (15), and Maier-Speredelozzi et al. (11). As shown in Table 3, after congestion in a hypothetical evacuation is confronted, the rates at which participants expected to leave designated evacuation paths for alternate routes when they received information from the various sources were similar for all information sources. For example, when congestion was first confronted during an evacuation, approximately $30 \%$

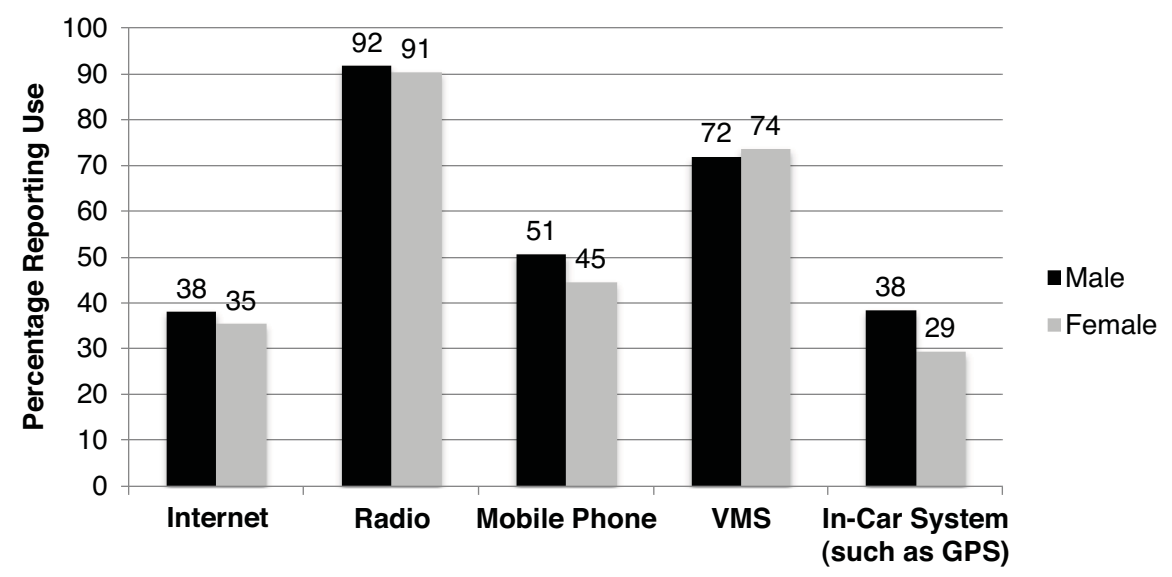

FIGURE 2 Reported uses of traffic information sources by gender.

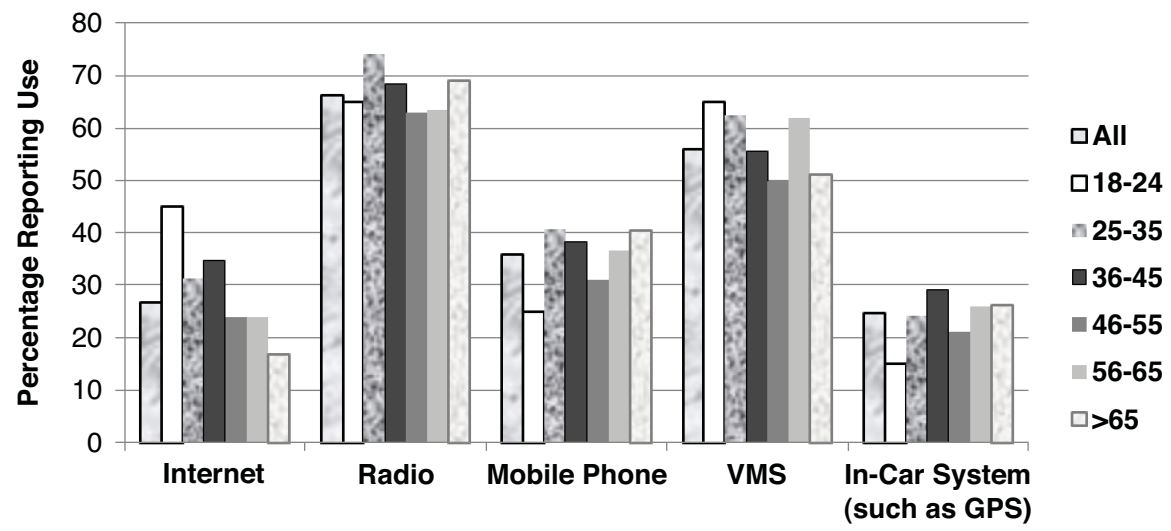

FIGURE 3 Reported uses of traffic information sources by age group. 
TABLE 3 Percentage of Evacuees Reporting Altering Routes When Receiving Traffic Information from Indicated Source at Each Time Increment After Confronting Congestion

\begin{tabular}{lcccccc}
\hline $\begin{array}{l}\text { Time } \\
(\mathrm{min})\end{array}$ & Overall & Radio & VMS & Mobile Phone & GPS & Internet \\
\hline 0 & 30.7 & 30.4 & 30.8 & 28.3 & 35.2 & 30.6 \\
30 & 77.4 & 75.9 & 77.6 & 80.3 & 79.9 & 74.5 \\
60 & 81.6 & 81.0 & 81.5 & 81.4 & 81.9 & 83.3 \\
120 & 85.9 & 85.3 & 86.0 & 84.5 & 86.9 & 88.0 \\
\hline
\end{tabular}

of the users of all sources anticipated taking an alternate route. After being in congestion for $30 \mathrm{~min}$, approximately $77 \%$ of the users of all sources expected to divert. Additionally, the anticipated influence of all sources was higher than that reported in these earlier studies. This finding was especially true for higher-tech sources, which include mobile phones, GPS, and the Internet. The increased use and influence of ATISs support the suggestion of Mehndiratta et al. that increased familiarity with advanced technologies would lead to both increased use and reduced skepticism (4).

Figure 4 shows the relationship between the respondents' reported past use of each information source during routine driving and selfreported anticipation of diverting when they faced congestion during a hurricane evacuation. Although the number of respondents using each information source varied, the percentage of users expecting to detour was essentially equal for all time increments for each information source, indicating that each information source is ascribed the same level of credibility by its users. For example, $82 \%$ of the individuals in the sample population anticipated that after 60 min they would divert to avoid congestion during an evacuation. The proportion of users of each information source who anticipated that they would make route alterations was within $2.5 \%$ of this value. This result essentially suggests equal confidence in each information source by those using it. Figure 4 shows that for all information sources, the chance that users would take an alternate route increases the longer that they face the congested period. This observation was true even when no information was provided. Even without the provision of any information on alternate routes, if congestion continued for $1 \mathrm{~h}$, the proportion of evacuees who would alter their routes increased from $30 \%$ to $45 \%$.

\section{Application of Information Source Results}

The survey results show that the evacuating drivers questioned for this study anticipate that they would use ATISs more frequently and that ATISs would have greater influence during evacuations than the frequency and influence reported 3 or more years earlier for routine traffic situations. The results do not allow determination of whether the increase is caused by an increased credibility of ATIS technologies, increased familiarity with advanced technology, or the hypothetical emergency situation given to survey participants. However, the data show that a significant number of drivers use these systems and planning officials would be wise to ensure that the well-focused use of ATISs is part of routine and emergency situation traffic management plans. As noted by Wolshon et al., traditional ATISs, including VMSs and highway advisory radio, are not well supported outside of urban areas (3). The three advanced technology sources (GPS, mobile phones, and the Internet) do not necessarily share this limitation. An increased emphasis on these sources may help fill the information gap resulting from geography.

Forty-four survey questions or statement evaluations addressed traffic information content, frequency of use, and influence by use of a five-level Likert scale. Significance assessments used confidence intervals, chi-square distribution testing, and Welch's $t$-test with significance $p$-values of .05 or less. Four types of information were provided via VMSs

1. "Accident ahead,"

2. "Accident ahead" and alternate route guidance,

3. The same as the first two types as well as information on the availability of services, and

4. Alternate route information with on-scene state police guidance.

Evacuees' anticipated rate of taking alternate routes increased as information that increased perceptions of safety and well-being was provided. For example, information on the availability of services resulted in an average increased likelihood of diversion of $6.4 \%$ over that from the provision of information on an alternate route alone. The highest rate of expected alternate route use was anticipated when state police were present: an average increase of $9.4 \%$ over alternate route information alone.

The relationship between previous route changes made as a result of prompting by the message on a VMS and the reported intention to

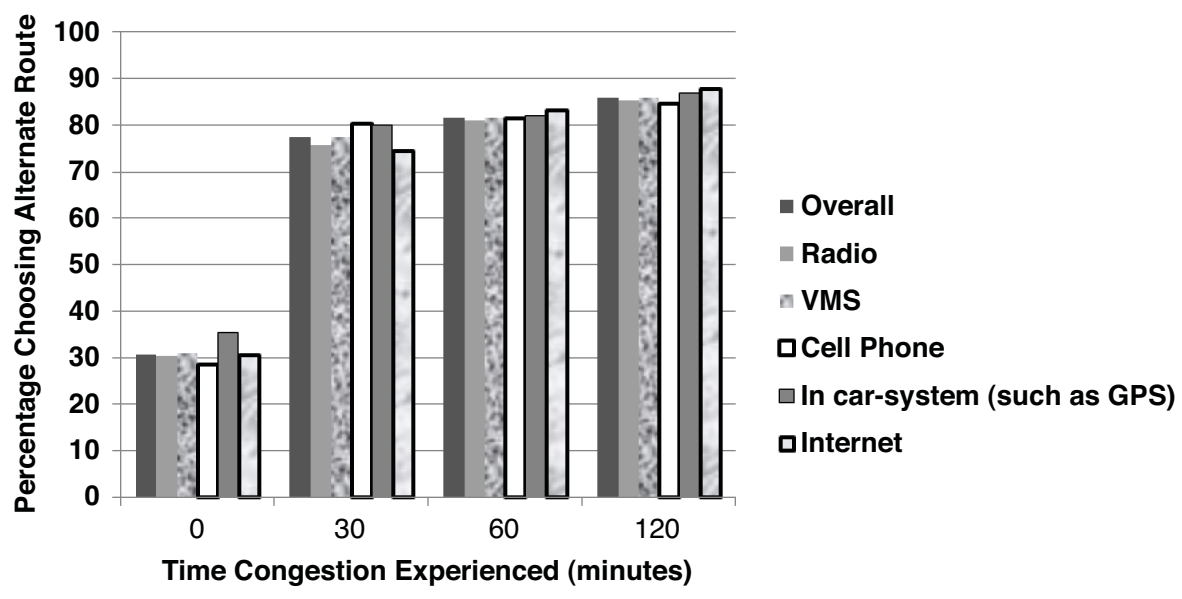

FIGURE 4 Percentage of evacuees reporting use of the indicated information source and anticipating diverting at each time increment. 
detour during an evacuation reported in the survey was assessed. Although the proportion of respondents $(72 \%)$ who reported that they had previously detoured as a result of prompting by a message on a VMS was the same as that expected to detour during a congested evacuation, $25 \%$ of these were in one group but not the other. This disparity prevented the marker comprising the influence of the message on a VMS from being used to forecast decisions in the congested evacuation scenario.

In general, males were less concerned that they might lose their way on alternate routes, reporting a significantly greater propensity to take risks (such as driving all night), greater comfort reading and following maps, and less unease about leaving major roads for alternative routes. Males were also more likely to claim advanced evacuation preparation. Females were more likely to say that they usually try to stay on main roads to avoid becoming lost. Despite the differences in attitudes, males and females indicated an equal propensity to divert when they were placed in an evacuation scenario with congestion.

Respondent age could also be associated with some evacuation factors, but like gender, it had no significant impact on the route choice made for the sample population. Older evacuees were more likely than younger adults ( 25 to 35 years of age) to have prepared for an evacuation. In view of the large portion of the population that comprised this younger group (18\%), it is important that planners be able to reach this group with information that convinces them of the importance of advance preparations.

\section{Factor Analysis}

Factor analysis identifies relationships between the different responses and group responses most strongly associated with one another into a few components, each of which represents the combined influence of the related variables. This can simplify analysis and make it easier to recognize and understand the relationships between variables. A factor analysis of survey participant responses sought the level of user agreement with 22 statements about normal driving behavior and patterns by use of a Likert scale.

Table 4 provides the results of the factor analysis calculated with SPSS software. The primary component analysis method was used, and initial component selection was made by filtering for eigenvalues greater than 1.0 and by assessing the scree plots provided. Components were rotated by using the Varimax option. Five components were suggested; the fifth was dropped because it represented only one statement and it was better matched with the first suggested component. Component values of less than 0.4 were suppressed for display. The four components can separate evacuees into four driver types and are (subjectively) titled

1. Experienced and cautious,

2. Confident and prepared,

3. Information seeking, and

4. Aggressive.

TABLE 4 Factor Analysis Component Matrix

\begin{tabular}{|c|c|c|c|c|}
\hline \multirow[b]{2}{*}{ Statement } & \multicolumn{4}{|c|}{ Component Name ${ }^{a}$} \\
\hline & $\begin{array}{l}\text { Experienced } \\
\text { and Cautious } \\
(21 \%)\end{array}$ & $\begin{array}{l}\text { Confident } \\
\text { and Prepared } \\
(15 \%)\end{array}$ & $\begin{array}{l}\text { Information } \\
\text { Seeking } \\
(10 \%)\end{array}$ & $\begin{array}{l}\text { Aggressive } \\
(6 \%)\end{array}$ \\
\hline I have previously diverted using information from a VMS. & .647 & & .465 & \\
\hline I have previously diverted using information from a temporary VMS. & .618 & & & \\
\hline I have previously diverted using information from radio. & .612 & & & \\
\hline I am willing to take risks and divert to avoid delays. & .556 & .461 & & \\
\hline I watch for traffic information on VMS. & 546 & & .517 & \\
\hline Radio reports should provide delay estimates. & .534 & & & \\
\hline I am comfortable diverting if state police are present. & .530 & & & \\
\hline I enjoy finding new routes to my destination. & .508 & & & \\
\hline VMS information is usually accurate. & 507 & & .453 & \\
\hline I usually stay on main roads to avoid getting lost. & -.500 & & 467 & \\
\hline I usually outwait jams to avoid getting lost. & -.469 & & 435 & \\
\hline I am comfortable reading highway maps. & .467 & & & \\
\hline I check radio reports for traffic information before starting trips. & .456 & & & \\
\hline I prefer that a VMS provide delays using time, not distance. & .444 & & & \\
\hline I am willing to divert to avoid delays. & & .731 & & \\
\hline I am uneasy leaving main roads without knowing service availability. & & -.677 & & \\
\hline I am reluctant to divert from main highways. & & -.660 & & \\
\hline I always have a map in the car. & & .534 & & \\
\hline I get impatient quickly when stuck in traffic. & & .453 & & .428 \\
\hline I am an aggressive driver. & & 445 & & .444 \\
\hline I watch for traffic info on VMSs. & & 404 & .651 & \\
\hline I am suspicious of traffic delays reported on VMSs. & & & & .477 \\
\hline
\end{tabular}

${ }^{a}$ These four component groups account for $52 \%$ of the total variance in all survey responses for the 22 statements. 
The four components combined account for $52 \%$ of the total variance for the 22 statements. The percent values after each component's name indicate the percentage of all variance accounted for by the individual component.

As can be seen in Table 4, several statements had high values (greater than 0.400) for factor loadings (correlations between the variable and the factor) when they were associated with two components. By use of the suggested guidance of Pett et al. (16), these component assignments were made when each statement most reasonably fit and not necessarily when the highest magnitude was calculated. To clarify statement assignments to components, values to which the statement was not assigned are crossed out (e.g., $\theta .465)$. The calculated Bartlett's test of sphericity chi-square value was 6,194 , far greater than the corresponding value for a significance $(p)$ value of .05 . This result confirms that the correlation matrix is not an identity matrix, supporting use and application of factor analysis.

Experienced and cautious drivers tend to stay on main roads but are willing to divert to alternate routes when they are provided information via ATISs. Confident and prepared drivers have little hesitation about leaving main roads for alternates. They carry maps and appear to rely on their own abilities more than on external information sources, although sources may be considered if they are available. Information seekers look for traffic information but generally do not adjust their plans in response to information received. The receipt of information may perhaps relieve anxiety, but it is unlikely to influence the traffic situation. Aggressive drivers quickly grow impatient with congestion and apparently have little confidence in VMS information. They do not tend to act on information any differently than the overall population. Perhaps these are the drivers who constantly shift lanes in congestion but arrive at their destinations no sooner than others; this aspect of driving and their success at reducing travel times compared with the success of others was not investigated in the survey.

\section{Application of Information Content Results}

The majority of drivers claim to seek and use information provided by ATISs to decide on or alter routes during routine travel and also expect to use ATISs under emergency conditions. Responses indicated a greater likelihood of diversion when information that increased drivers' confidence in both the route and the available services was provided. However, a significant portion of the sample population $(22 \%)$ reported having little confidence in traffic information provided via a VMS when the population was questioned in the survey. Results indicate that actions and information that enhance evacuees' sense of security and confidence in alternate routes may increase their likelihood of taking alternate routes. Analysis indicates that targeting two of the identified four groups with ATISs may provide the best results.

Experienced and cautious drivers pay attention to traffic information and want to know how long delays are expected to persist. Given good information, they are likely to follow route guidance. To influence confident and prepared drivers, the credibility of VMSs should be enhanced. Because relatively few members of the sample population had ever participated in a large-scale hurricane evacuation and none had done so in Hampton Roads, Virginia, more attention must be paid to VMS accuracy in day-to-day operations. Emergency management and transportation officials may use this knowledge to provide (or withhold) information to prompt desired driver actions. Emergency planners might find it useful to provide tailored informa- tion to certain groups. System performance could benefit by having all drivers equally well prepared.

\section{LIMITATIONS}

The scope and assumptions of the analysis are noteworthy:

- The survey was intended to gather sufficient information to provide data for behavior-based testing. Given resource constraints, a representative sample of the region's population could not be obtained. In particular, younger and lower-income citizens were underrepresented. The high number of survey responses provides some mitigation, but before these results are used in a real-world situation, a regionally specific, demographically accurate survey must be conducted.

- The survey and subsequent analyses target residents in the Hampton Roads region of Virginia. Results should not be directly applied to other areas without further study. However, Hampton Roads is a large metropolitan area with approximately 1.7 million residents and includes urban, suburban, and rural areas. The region has more than $600 \mathrm{mi}$ of primary and Interstate roadways and includes almost 1,500 bridges and five tunnels. These characteristics improve the value of the study to other regions.

- Analysis assumes that the behavior of current users of traffic information and the influence of that information are reasonably related to what would be expected in an emergency evacuation scenario.

- Analysis relies on the use and influence of traffic information claimed by the sample population. It has not been validated by any observed or actually exhibited behavior. In any survey questioning the future intentions of respondents, one must keep in mind that intentions may differ from the actions that are actually taken during an event.

\section{CONCLUSIONS}

This research sought insight into the traffic information sources that might be expected to be used with the greatest frequency during a hurricane evacuation and into the information content with the greatest anticipated influence on potential hurricane evacuees. Behavioral survey responses were obtained from more than 800 adult drivers in the Hampton Roads region of Virginia. The fraction of drivers in the sample population that obtained and acted on traffic information for their daily routine travel was much larger than that reported in previous studies.

Although radio and VMSs remain the most frequent sources of traffic information, increased use of the newer technology systems was especially evident, with more than one in three drivers using one of the three newer methods. This rate of use far exceeds that reported for the Seattle, Washington, region in 1997 by Mehndiratta et al. (4) and is more than double that reported for Rhode Island in 2005 by Maier-Speredelozzi et al. (11). This shift in traffic information sources must be considered by emergency management and transportation officials. The influence that individual traffic information sources had on its adherents was essentially constant: the same proportion of those using VMS information as those using one of the other information sources acted on that information.

Installation costs of permanent VMSs and supporting structures can be $\$ 120,000$, and portable systems may cost $\$ 20,000$ to $\$ 25,000$, in addition to annual maintenance costs and the costs of monitoring 
and updating signs with current information. In contrast, users of GPSs pay their own system expenses, with little, if any, government contribution to system costs required. Mobile phone and Internet users can take advantage of the availability of free realtime traffic applications (e.g., INRIX and Google Traffic). Even relatively modest adjustments to government funding to provide support for locally enhanced GPS or mobile phone applications may improve ATIS use rates and influence.

Responses to questions concerning traffic information sources support the findings of previous studies of routine commuting, but they also appear to show an evolution in habits. Although radio remains the most frequently used source of information, significant increases in the use of the more modern sources, such as GPSs, the Internet, and mobile telephones, were reported. Almost all respondents used more than one source of information, with radio, VMSs, or phone systems used by $98 \%$ of respondents. Efforts to ensure good information distribution should clearly target these three sources.

Factor analysis identified two groups of drivers, named experienced and cautious drivers and confident and prepared drivers, for whom ATISs may provide the greatest benefit. Enhancements to ATISs that address the needs of these two groups may likely provide substantial improvements to evacuation traffic system performance.

Survey results also provided insight into the content of information of the greatest use to evacuees. Evacuees will be more likely to divert to alternate routes and facilitate dynamic readjustment of traffic to less congested roadways if the information provided increases their confidence in safety or well-being. Future research will integrate the survey results into evacuation simulations and forecasts of future traffic patterns and ATIS use.

\section{ACKNOWLEDGMENTS}

The authors appreciate the support provided by the Virginia Modeling, Analysis, and Simulation Center and the Old Dominion University Transportation Research Institute.

\section{REFERENCES}

1. Dow, K., and S. L. Cutter. Public Orders and Personal Opinions: Household Strategies for Hurricane Risk Assessment. Global Environmental Change Part B: Environmental Hazards, Vol. 2, No. 4, 2000, pp. 143-155.

2. Prater, C. S., D. Wenger, and K. Grady. Hurricane Bret Post Storm Assessment: A Review of the Utilization of Hurricane Evacuation Studies and Information Dissemination. Texas A\&M University Hazard Reduction and Recovery Center, College Station, 2000. http://archone. tamu.edu/hrrc/Publications/researchreports/index.html. Accessed June $16,2009$.
3. Wolshon, B., E. U. Hamilton, M. Levitan, and C. Wilmot. Review of Policies and Practices for Hurricane Evacuation. II. Traffic Operations, Management, and Control. Natural Hazards Review, Vol. 6, No. 3, 2005, pp. 143-161.

4. Mehndiratta, S. R., M. A. Kemp, J. E. Lappin, and E. Nierenberg. Likely Users of Advanced Traveler Information Systems: Evidence from the Seattle Region. In Transportation Research Record: Journal of the Transportation Research Board, No. 1739, TRB, National Research Council, Washington, D.C., 2000, pp. 15-24.

5. Goulias, K. G., T.-G. Kim, and O. Pribyl. A Longitudinal Analysis of Awareness and Use for Advanced Traveler Information Systems. Journal of Intelligent Transportation Systems, Vol. 8, No. 1, 2004, pp. 3-17.

6. Khattak, A. J., J. L. Schofer, and F. S. Koppelman. Factors Influencing Commuters' En Route Diversion Behavior in Response to Delay. In Transportation Research Record 1318, TRB, National Research Council, Washington, D.C., 1991, pp. 125-136.

7. Khattak, A., A. Polydoropoulou, and M. Ben-Akiva. Modeling Revealed and Stated Pretrip Travel Response to Advanced Traveler Information Systems. In Transportation Research Record 1537, TRB, National Research Council, Washington, D.C., 1996, pp. 46-54.

8. Khattak, A. J., X. Pan, B. M. Williams, N. M. Rouphail, and Y. Fan. Traveler Information Delivery Mechanisms: Impact on Consumer Behavior. In Transportation Research Record: Journal of the Transportation Research Board, No. 2069, Transportation Research Board of the National Academies, Washington, D.C., 2008, pp. 77-84.

9. Scheisel, R., and M. J. Demetsky. Evaluation of Traveler Diversion Due to En-Route Information. Mid-Atlantic Universities Transportation Center Report UVA/29472/CE00/103. Virginia Department of Transportation and U.S. Department of Transportation, Charlottesville, 2000.

10. Levinson, D., and H. Huo. Effectiveness of VMS Using Empirical Loop Detector Data. Presented at 82nd Annual Meeting of the Transportation Research Board, Washington, D.C., 2003.

11. Maier-Speredelozzi, V., J.-H. Wang, C. Collyer, N. Thomas, A. Clark, J. Severson, and K. S. Chaparro. Disseminating Information with Variable Message Signs During Natural or Human-Caused Disasters. European Conference of Transport Research Institutes, Young Researchers Seminar, May 27-30, 2007, Brno, Czech Republic. www.ectri.org/ YRS07/Papiers/Session-15/Mayer-Speredelozi.pdf. Accessed July 29, 2010.

12. Ye, Z., J. Chaudhari, J. Booth, and B. Posadas. Evaluation of the Use of Rural Transportation Infrastructure in Evacuation Operations. Journal of Transportation Safety and Security, Vol. 2, No. 2, 2010, pp. 88-101.

13. Robinson, R. M., and A. Khattak. Route Change Decision Making by Hurricane Evacuees Facing Congestion. In Transportation Research Record: Journal of the Transportation Research Board, No. 2196, Transportation Research Board of the National Academies, Washington, D.C., 2010, pp. 168-175.

14. Robinson, R. M. Modeling Decision Making Related to Incident Delays During Hurricane Evacuations. PhD dissertation. Old Dominion University, Norfolk, Va., 2010.

15. Yim, Y., A. J. Khattak, and J. Raw. Traveler Response to New Dynamic Information Sources: Analyzing Corridor and Areawide Behavioral Surveys. In Transportation Research Record: Journal of the Transportation Research Board, No. 1803, Transportation Research Board of the National Academies, Washington, D.C., 2002, pp. 66-75.

16. Pett, M. A., N. R. Lackey, and J. J. Sullivan. Making Sense of Factor Analysis. Sage Publications, Thousand Oaks, Calif., 2003.

The Transportation Safety Management Committee peer-reviewed this paper. 